\title{
DEVELOPMENT OF A HIGH PERFORMANCE CHROMATOGRAPHIC METHOD FOR THERAPEUTIC DRUG MONITORING OF CARBAMAZEPINE BASED ON AN EXPERIMENTAL DESIGN APPROACH
}

\author{
CRISTIAN TUCHILA ${ }^{1 \#}{ }^{1 \#}$, DANIELA BACONI ${ }^{1 *} *$, VALENTINA ANUȚA ${ }^{1 \#}$, CRISTINA ELENA \\ DINU-PÎRVU ${ }^{1 \#}$, ANA-MARIA VLĂSCEANU ${ }^{1 *}$, CRISTIAN BĂLĂLĂU ${ }^{2 \#}$, MARIA MAGDALENA \\ CONSTANTIN $^{3 \#}$, MIRIANA STAN ${ }^{1 \#}$ \\ I "Carol Davila” University of Medicine and Pharmacy, Faculty of Pharmacy, 6 Traian Vuia Street, Bucharest, Romania \\ 2 "Carol Davila" University of Medicine and Pharmacy, Faculty of Medicine, Sf. Pantelimon Emergency Clinical Hospital, \\ 340-342 Pantelimon Avenue, Bucharest, Romania \\ 3 "Carol Davila” University of Medicine and Pharmacy, Faculty of Medicine, Colentina Clinical Hospital, 19-21 Ștefan cel \\ Mare Boulevard, Bucharest, Romania
}

*corresponding author: daniela baconi@yahoo.com

\#All authors had equal contribution

Manuscript received: December 2017

\begin{abstract}
An isocratic simple and rapid HPLC-UV method has been developed and validated for the determination of carbamazepine (CBZ) in human plasma, using nitrazepam (NTZ) as internal standard. Separation was carried out on a C18 column with a mobile phase composed of water:acetonitrile $(55: 45 \mathrm{v} / \mathrm{v})$, delivered at a flow rate of $1 \mathrm{~mL} / \mathrm{min}$. Liquid-liquid extraction with ethyl acetate was used for the isolation of the analytes from plasma. Development of the method was based on a design of experiments (DOE) approach. A $2^{3}$ full factorial design with central points was used in order to select the experimental parameters, while considering peak asymmetry, resolution between CBZ and the internal standard and retention time as responses. Overall, optimization of the analysis parameters was performed using Derringer's desirability function and overlay contour plots. The method was fully validated in the concentration range of $0.1-20 \mu \mathrm{g} / \mathrm{mL}$, which included the entire therapeutic range of CBZ $(4-12 \mu \mathrm{g} / \mathrm{mL}$ ). The method is simple, rapid (with a total analysis time of 5 minutes) and can be applied in routine clinical investigations.
\end{abstract}

\section{Rezumat}

A fost dezvoltată și validată o nouă metodă lichid cromatografică pentru determinarea cantitativă a carbamazepinei (CBZ) din plasma umană, utilizând nitrazepamul ca standard intern. Separarea a fost realizată pe o coloană de tip C18, utilizând o fază mobilă conținând un amestec de apă și acetonitril, în raport volumic 55:45. Debitul fazei mobile a fost de $1 \mathrm{~mL} / \mathrm{min}$. Izolarea analiților din probele de plasmă s-a realizat prin extracție lichid-lichid, folosind acetatul de etil drept solvent de extracție. Dezvoltarea metodei a fost realizată utilizând tehnici de design experimental. A fost utilizat un design de tip factorial, cu trei factori la 2 nivele $\left(2^{3}\right)$, considerându-se ca și răspunsuri asimetria picurilor, rezoluția între CBZ și standardul intern, precum și timpul de retenție al analiților. Pentru optimizarea parametrilor, s-au utilizat gradul de dezirabilitate şi graficele de contur suprapuse. Metoda a fost validată pe un interval de concentrații între 0,1 și $20 \mu \mathrm{g} / \mathrm{mL}$, care include zona terapeutică a CBZ (4 - $12 \mu \mathrm{g} / \mathrm{mL})$. Metoda este simplă, rapidă (cu un timp total de analiză de 5 min) şi poate fi aplicată în monitorizarea terapeutică a CBZ.

Keywords: carbamazepine, HPLC, design of experiments, therapeutic drug monitoring

\section{Introduction}

Carbamazepine (CBZ) is a tricyclic iminostilbene derive that is used as a first line drug in the treatment of trigeminal neuralgia, temporal lobe epilepsy and other convulsive disorders [6].

Therapeutic CBZ concentrations have been reported to be in the range of $6-12 \mu \mathrm{g} / \mathrm{mL}$ [6], although significant variations may arise. Its high pharmacokinetic variability often leads to poor correlation between drug dosage and drug pharmacologic effects
[24], since the therapeutic outcome is related to CBZ concentration reaching the systemic circulation, rather than to the administered dosage [28].

Being both a highly variable and a narrow therapeutic index drug [14], CBZ is a good candidate for therapeutic drug monitoring (TDM).

TDM provides a valuable tool to further understand the lack of therapeutic outcome of the therapy in specific cases, as well as the inter-individual pharmacokinetic variability and the factors responsible. Furthermore, TDM can help distinguish between ineffective drug 
FARMACIA, 2018, Vol. 66, 3

treatment, non-compliance and adverse effects that mimic the underlying disease, and therefore be a useful tool in providing safe dosage regimens in therapy [17]. In the particular case of CBZ, usefulness of TDM is widely recognized [23]. However, in order to perform a successful TDM using the quantitative determination of specific drugs in body fluids, sensitive and selective analytical methods are needed [1, 4]. Numerous methods have been reported for the analysis of CBZ in biological samples, using RPHPLC coupled with UV or MS detection and C18 [5, 8, 11, 18, 20, 25, 27], C8 [9] or C14 [29] stationary phases. Other methods include HPTLC [21] or immunoassay [19] techniques. Several methods were developed and used for permeability studies [16, 22]. A comparison of the previously employed analytical methods for determination of CBZ has been previously published [28].

The aim of the present study was the development and validation of a new, simple and rapid HPLCUV method for the quantitative evaluation CBZ, appropriate for routine TDM purposes, using a Design of Experiments (DOE) approach.

The DOE techniques include the use of experimental design, generation of mathematical equations and graphic outcomes [15]. By means of multivariate analysis techniques, the experimental design fits the experimental data into mathematical equations (models), in order to predict and optimize the studied parameters (responses) [12, 13]. Application of DOE in HPLC development and optimization is recent, but the advantages over conventional approaches are significant $[3,26]$. As compared to the present CBZ methods, this approach provides a better insight into the sensitivity of chromatographic factors and their interaction effects on the performances of the chromatographic separation and allows a more efficient optimization of the separation.

\section{Materials and Methods}

\section{Chemicals}

Carbamazepine (European Pharmacopoeia reference standard) was purchased from the European Directorate for the Quality of Medicines (EDQM, Strasbourg, France), whereas nitrazepam (NTZ), used as internal standard (IS) was acquired from Sigma-Aldrich (St. Louis, MO, USA). HPLC grade acetonitrile and methanol were purchased from Merck KGaA, Germany. The water for chromatographic use (resistivity 0.055 $\mu \mathrm{S} / \mathrm{cm}$, TOC $<5 \mathrm{ppb}$ ) was obtained by reversed osmosis using a Barnstead ${ }^{\circledR}$ Easysure RoDi system. All other reagents were of analytical grade, obtained from different commercial suppliers and used without further purification.

Instrumentation

The tests were carried out using a Thermo ${ }^{\circledR}$ Surveyor Plus High Performance Liquid Chromatograph (Thermo
Fisher Scientific, Waltham, MA, USA) equipped with quaternary pump, automated sampling system, Peltier thermostated column compartment and diode array detector (DAD). Data acquisition, monitoring and processing of output chromatograms were performed using Chromquest 4.1 system control software.

An Adventurer ${ }^{\circledR}$ analytical balance (OHAUS Corp., Greifensee, Switzerland) was used for the weighing of standard substances. The mobile phase solution was filtered through a $0.45 \mu \mathrm{m}$ membrane filter using a glass vacuum filtration assembly (Millipore Corp., Bedford, MA, USA) and degassed by sonication using a S60 $\mathrm{H}$ ultrasonic bath (Elma $\mathrm{GmbH}$, Singen, Germany).

Chromatographic conditions

Separation was achieved on a Hypersil BDS C18 $5 \mu \mathrm{m}$, $4.6 \times 125 \mathrm{~mm}$ column (Thermo Fisher Scientific, Waltham, MA, USA), maintained at $22^{\circ} \mathrm{C}$. The mobile phase consisted of a water:acetonitrile $(55: 45 \mathrm{v} / \mathrm{v})$ mixture, delivered at a flow rate of $1.0 \mathrm{~mL} / \mathrm{min}$. Detection of the analytes was performed using a diode array detector (DAD) set at $285 \mathrm{~nm}$ (with full recording of the spectrum between $200 \mathrm{~nm}$ and $400 \mathrm{~nm}$ ). The total run time was of 5 minutes.

Blank human plasma was obtained from the Army Centre of Transfusion Haematology (Bucharest, Romania).

\section{Standard solutions}

Stock standard solution of CBZ and NTZ were prepared in methanol at a concentration of $1 \mathrm{mg} / \mathrm{mL}$. The prepared stock solutions were stored protected from light, at $4^{\circ} \mathrm{C}$. For development and optimization purposes, a working solution containing $25 \mu \mathrm{g} / \mathrm{mL}$ CBZ and $25 \mu \mathrm{g} / \mathrm{mL} \mathrm{NTZ} \mathrm{was} \mathrm{freshly} \mathrm{prepared} \mathrm{by}$ diluting the stock standard solution with mobile phase in the day of analysis.

The calibration standards were prepared by spiking blank plasma samples with the appropriate amounts of CBZ standard solution in order to obtain standards at concentrations of $0.1,0.5,1,2,4,8,12$ and $20 \mu \mathrm{g} / \mathrm{mL}$. Quality control (QC) samples were prepared independently, in a similar way, by diluting the mixed working solution to obtain low (QC3), medium (QC2) and high (QC1) concentrations. All plasma samples were immediately divided into $1.5 \mathrm{~mL}$ polypropylene microcentrifuge tubes maintained at $-20^{\circ} \mathrm{C}$ and thawed immediately prior to analysis.

Sample extraction

In order to isolate CBZ and NTZ from the biological matrix, a liquid-liquid extraction procedure was applied. Briefly, $50 \mu \mathrm{L}$ of $100 \mu \mathrm{g} / \mathrm{mL} \mathrm{NTZ} \mathrm{in} \mathrm{methanol}$ were mixed with $1000 \mu \mathrm{L}$ of plasma sample for 1 minute. Then, $250 \mu \mathrm{L}$ of $25 \%$ ammonia solution and $4 \mathrm{~mL}$ of ethyl acetate were added and the resulting sample was vortex-mixed for another 3 minutes. Finally, $100 \mu \mathrm{L}$ of isopropanol along with a few crystals of sodium chloride were added. The mixture was further vortex-mixed for 15 minutes, transferred 
into centrifuge tubes and centrifuged for 15 minutes at approximately $4500 \mathrm{G}$ and $8^{\circ} \mathrm{C}$. The upper layer was retrieved and evaporated at $40^{\circ} \mathrm{C}$, under nitrogen stream (about 30 minutes). The dried residue was reconstituted with $500 \mu \mathrm{L}$ of mobile phase and sonicated for 5 minutes. The resulting sample was transferred into a HPLC vial for analysis.

\section{Assay validation}

The method was validated according to the Food and Drug Administration (FDA) guidance for Bioanalytical Method Validation, including selectivity, linearity, accuracy, precision, recovery and stability [10]. Specificity was evaluated in relation to interferences from endogenous matrix components from drugfree plasma sample of different origin.

The calibration curve was constructed using eight concentration levels in the range of $0.1-20 \mu \mathrm{g} / \mathrm{mL}$. The peak-area ratios of the CBZ to the internal standard were calculated and plotted against the nominal analyte concentration. The correlation between the two parameters was established by least squares linear regression analysis. Each sample was analysed in triplicate.

Evaluation of the detection limit (LOD) and quantification limit (LOQ) was performed based on the signal-to-noise ratio. The concentrations yielding to signal-to-noise ratios of $3: 1$ and 10:1 were considered as LOD and LOQ, respectively.

Intra-day accuracy and precision were evaluated for the three QC samples from the results of five replicate analyses, whereas for estimation of the inter-day accuracy and precision replicates at each QC levels were performed in different days. The accuracies were considered adequate if the calculated values were within $15 \%$ of the nominal concentration (or $20 \%$ at LOQ). The precision of samples was acceptable if the relative standard deviation (\% RSD) was not exceeding $15 \%$ for all levels except LOQ, where the limit is $20 \%$.

The stability studies were designed to mimic as close as possible the long-term storage of plasma samples, stock solutions and extracted samples in the autosampler awaiting analysis. The stability of stock solution was investigated for three months at $2-8^{\circ} \mathrm{C}$, the processed samples stability was evaluated for 24 hours, whereas stability of the unprocessed plasma samples was screened for 3 weeks at $-20^{\circ} \mathrm{C}$ and after 3 freeze-thaw cycles.

Statistical analysis

The experimental design for the optimization along with data analysis, response surfaces and contour plots related to the DOE approach were performed using the trial version of Design-Expert 11.0 software (Stat-Ease, Inc., Minneapolis, MN, USA).

The other statistical analyses as well as graphical representation of data were performed using Graph
Pad Prism 7 (GraphPad Software Inc., La Jolla, CA, United States) software.

\section{Results and Discussion}

\section{Method development}

A mixed approach strategy was employed in the development and optimization of the HPLC method, employing a screening step performed through the traditional approach of changing one factor at a time (OFAT approach), whereas optimization of the experimental parameters was done through DOE. Nitrazepam (NTZ) was selected as internal standard (IS), due to its similarity with carbamazepine, both structural and in terms of partition properties.

The initial screening tests allowed selection of the chromatographic column, mobile phase components, CBZ extraction method, as well as identification of the critical values of some experimental values, e.g. the maximum amount of organic modifier in the mobile phase that ensured $\mathrm{CBZ}$ retention on the chromatographic column.

Screening of different C18-based columns allowed selection of a Hypersil BDS C18 $5 \mu \mathrm{m}, 4.6$ x $125 \mathrm{~mm}$ column (Thermo Fisher Scientific, Waltham, MA, USA), which provided the best peak shape and resolution between CBZ and NTZ.

Generally, in order to keep the molecule in the unionized form, and therefore to ensure better retention in a reversed-phase system, it is important to maintain the $\mathrm{pH}$ at 2 units above the $\mathrm{pKa}$ for the basic compounds and 2 units below the $\mathrm{pKa}$ for the acidic ones [3]. However, high $\mathrm{pH}$ is not compatible with most of the HPLC columns [2]. Therefore, an alternate approach of using an acidic mobile phase and maintaining the basic compounds in completely ionized form is generally preferred. However, CBZ, despite being a weak base, is not ionisable, hence variations in the $\mathrm{pH}$ of the mobile phase had virtually no effect on CBZ retention. However, NTZ has amphiphilic molecule, and therefore is partially ionized at $\mathrm{pH}$ values below 4.5. Using acidic $\mathrm{pH}$ mobile phase led to lower retention of NTZ and decreased resolution of the chromatographic separation. As a result, we chose not to perform any $\mathrm{pH}$ modification of the mobile phase (Figure 1).

Out of the commonly used organic modifiers in chromatography, acetonitrile (ACN) was selected, due to obtaining superior CBZ peak shape by comparison with methanol. A content of organic modifier below $65 \%(\mathrm{v} / \mathrm{v})$ was found to be critical in the separation, since, above this ACN concentration, $\mathrm{CBZ}$ was no longer retained on the column.

In order to isolate CBZ from the biological matrix, both liquid-liquid extraction (LLE) and protein precipitation (PP) with ACN were attempted. 

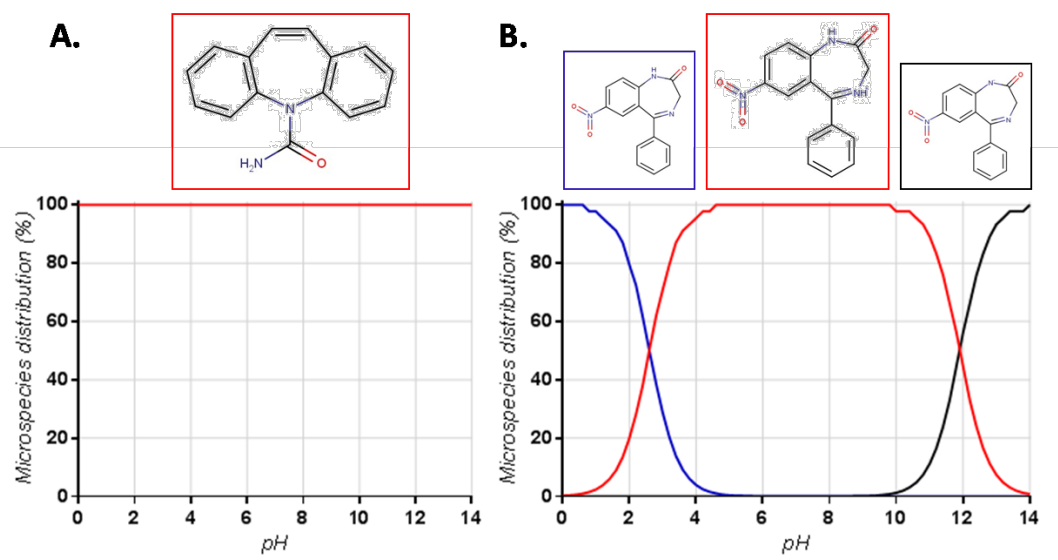

Figure 1.

Microspecies distribution (\%) for a) Carbamazepine and b) Nitrazepam; in both cases, the unionized form of the compound is plotted in red.

As PP has the advantages of speed and simplicity, an initial approach during method development was based on precipitation of plasma proteins with ACN.
Despite achieving high CBZ recovery (Table I), this approach resulted in a LOQ value 5 times higher than LLE, and therefore was discarded.

Table I

Performances of different CBZ isolation methods from plasma

\begin{tabular}{cccc}
\hline Method type & Organic solvent & Mean recovery (\%) & RSD (\%) \\
\hline LLE & Dichloromethane & 110.54 & 34.3 \\
LLE & Ethyl acetate & 96.28 & 2.6 \\
PP & Acetonitrile & 95.98 & 6.9 \\
\hline
\end{tabular}

\section{$\mathrm{LLE}=$ liquid-liquid extraction; $\mathrm{PP}=$ protein precipitation}

Dichloromethane and ethyl acetate were screened as extraction solvents in the LLE approach. The best results with respect to recovery, RSD and specificity were obtained for ethyl acetate (Table I). The $\mathrm{pH}$ of the plasma sample did not have significant influence on CBZ recovery (mainly due to the unionizable structure of the molecule). However, higher NTZ recovery as well as an overall lesser variability of the extraction process was obtained in weakly basic medium.

\section{Optimization of the HPLC method trough DOE}

Selection of the optimized variables was based on the preliminary OFAT experiments and on prior knowledge from the literature. The significance of the studied factors was evaluated by a full factorial design (FFD), followed by both a mathematical (Derringer's desirability function) and a graphical (overlay contour plots) approach in order to achieve global optimization of the separation process. Since FFD cannot account for curvature of the response surface, the design was augmented by using central points.

Three experimental factors varied at two levels were selected as independent variables: the percent of organic modifier in the mobile phase (A), the flow rate $(\mathrm{B})$ and the column temperature $(\mathrm{C})$. Three replicates of the central point were also included into the design. In order to minimize the effects of uncontrolled variables that may lead to biased measurements, the experiments were performed in randomized order. The resulted experimental matrix, presented in Table II, consists in a number of 11 experiments, of which 8 are factorial and 3 correspond to replicates of the central point.

The overall objective of our study was to ensure maximum resolution of the chromatographic separation, symmetric chromatographic peak shapes and to facilitate the accurate quantification of CBZ with minimum run time. Therefore, the selected responses were: asymmetry factor of the $\mathrm{CBZ}$ peak (AsC), coded as $\mathrm{Y}_{1}$ in the design, resolution of the chromatographic separation between CBZ and NTZ (Res), coded as $\mathrm{Y}_{2}$, as well as retention times of CBZ (RtC) and NTZ (RtN), coded as $\mathrm{Y}_{3}$ and $\mathrm{Y}_{4}$ respectively.

Introduction of the retention times in the design was performed in order to guarantee appropriate retention of $\mathrm{CBZ}$ (expressed through RtC) and a minimum run time (expressed through $\mathrm{RtN}$, since NTZ is the last eluting peak in the chromatogram). The experimental values for the investigated responses are presented in Table II. 
Table II

Experimental design matrix of the selected independent variables and measured responses for the applied FFD design

\begin{tabular}{|c|c|c|c|c|c|c|c|}
\hline \multirow{2}{*}{ Run no. } & \multicolumn{3}{|c|}{ Factor levels (actual values) } & \multicolumn{4}{|c|}{ Responses } \\
\hline & $A-A C N(\%)$ & B-Flow (mL/min) & C-Temperature $\left({ }^{\circ} \mathrm{C}\right)$ & $Y_{1}-A s C$ & $Y_{2}-\operatorname{Res}$ & $Y_{3}-R t C$ & $\mathrm{Y}_{4}-\mathrm{Rt} N$ \\
\hline 1 & 45.0 & 1.50 & 30.0 & 1.18 & 3.41 & 1.70 & 1.18 \\
\hline 2 & 52.5 & 1.25 & 26.0 & 1.19 & 2.73 & 1.74 & 1.19 \\
\hline 3 & 60.0 & 1.00 & 30.0 & 1.24 & 1.64 & 1.76 & 1.24 \\
\hline 4 & 60.0 & 1.50 & 30.0 & 1.27 & 1.22 & 1.10 & 1.27 \\
\hline 5 & 52.5 & 1.25 & 26.0 & 1.19 & 2.79 & 1.72 & 1.19 \\
\hline 6 & 45.0 & 1.50 & 22.0 & 1.17 & 3.72 & 1.69 & 1.17 \\
\hline 7 & 45.0 & 1.00 & 30.0 & 1.14 & 3.90 & 2.40 & 1.14 \\
\hline 8 & 52.5 & 1.25 & 26.0 & 1.20 & 2.82 & 1.73 & 1.20 \\
\hline 9 & 45.0 & 1.00 & 22.0 & 1.13 & 3.98 & 2.44 & 1.13 \\
\hline 10 & 60.0 & 1.50 & 22.0 & 1.24 & 2.01 & 1.09 & 1.24 \\
\hline 11 & 60.0 & 1.00 & 22.0 & 1.20 & 2.17 & 1.78 & 1.20 \\
\hline
\end{tabular}

In order to understand the impact of the independent factors as well as of their interaction on the separation quality, the experimental data were fitted according to a polynomial equation calculated by multiple regression analysis. The resulting model can be expressed as:

$Y=\beta_{0}+\beta_{a} A+\beta_{b} B+\beta_{c} C+\beta_{a} \beta_{b} A B+\beta_{a} \beta_{c} A C+\beta_{b} \beta_{c} B C$ where, $\mathrm{Y}$ is the response to be modelled, $\beta$ are regression coefficients for each main and interaction effects and $\mathrm{A}, \mathrm{B}$ and $\mathrm{C}$ represent the considered factors.

Significant factors influencing each response were identified by means of the half-normal plots and Pareto charts. Through backwards elimination, only
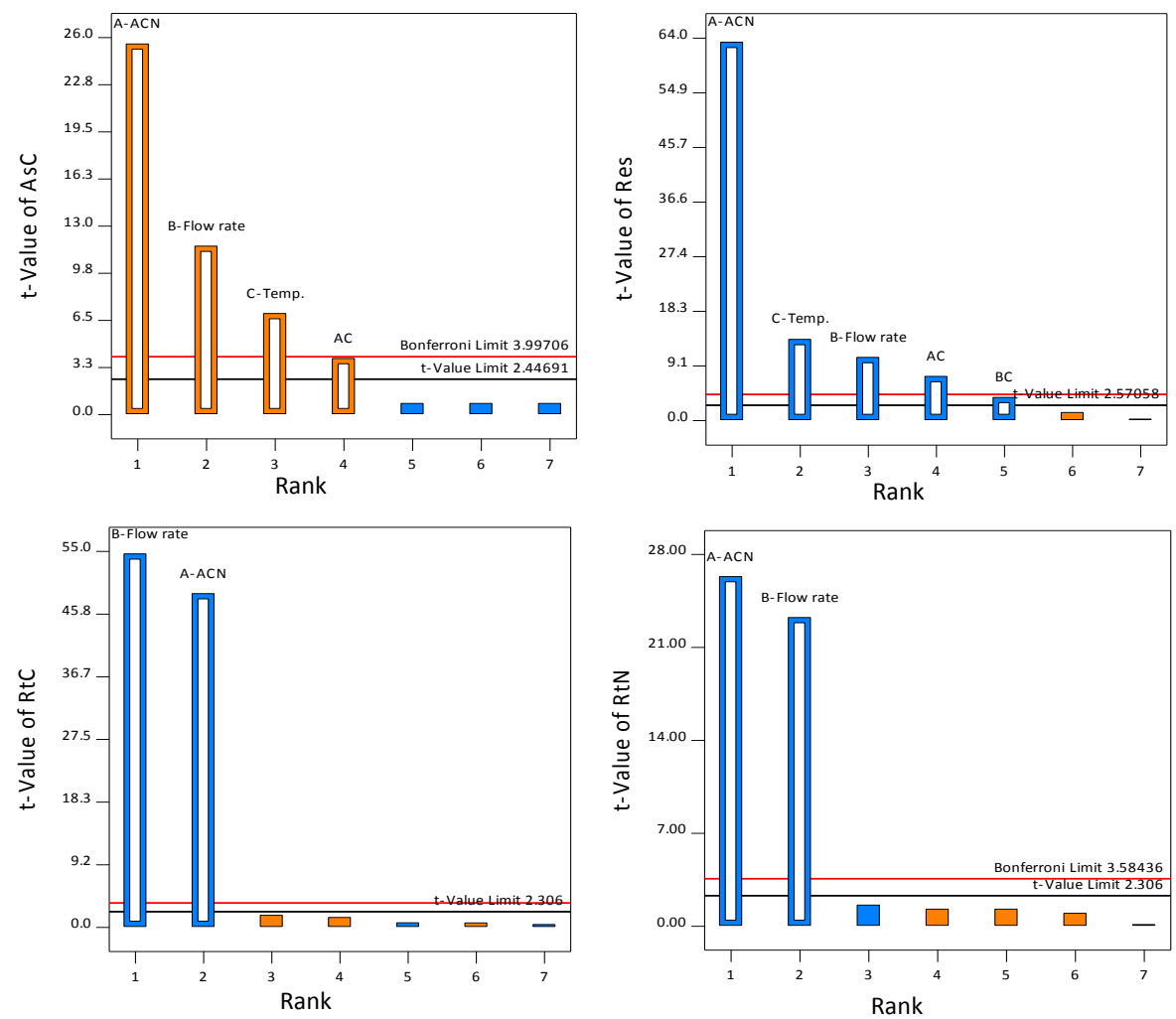

the significant terms $(\mathrm{p}<0.05)$ were retained and further subjected to the analysis of variance (ANOVA) test in order to obtain equation for each response, coefficient of determination $\left(\mathrm{R}^{2}\right)$, as well as to assess the quantitative and qualitative effects of the studied factors and of their interactions. The Pareto charts (Figure 2) as well as perturbation plots (Figure 3) emphasize that ACN percent (A) has the most important overall effect on the investigated responses, whilst temperature $(\mathrm{C})$ affected $\mathrm{CBZ}$ symmetry $\left(\mathrm{Y}_{1}\right)$ and resolution $\left(\mathrm{Y}_{2}\right)$ and had virtually no effect on the retention times $\left(\mathrm{Y}_{3}\right.$ and $\left.\mathrm{Y}_{4}\right)$.

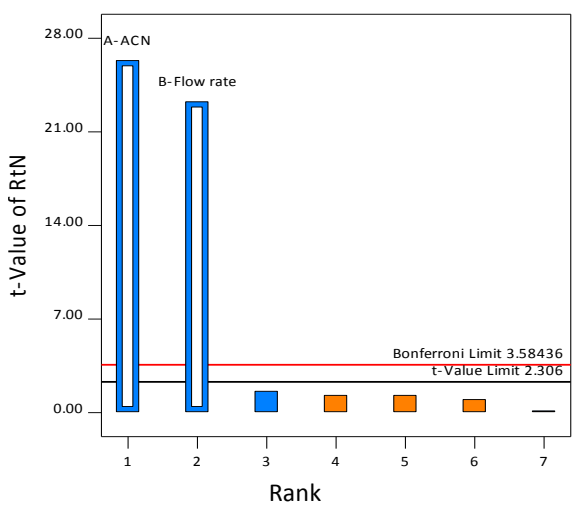

Figure 2.

Pareto charts for the investigated responses; negative effects are plotted in blue, whereas positive effects are orange. 
It is to note that all the investigated factors increased CBZ asymmetry (unwanted effect), but also increased resolution between the interest peaks (desired effect) (Figure 2).

A better understanding of the experimental effects can be obtained through examination of the perturbation plots (Figure 3). This type of graphs shows how an individual response changes as each factor moves
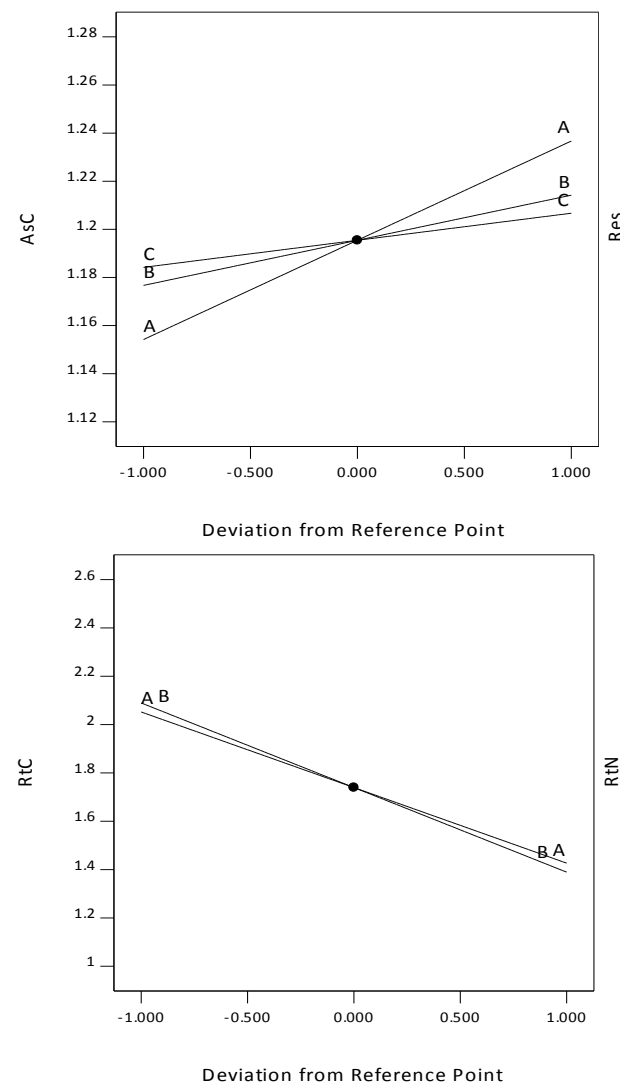

Figure 3.

Perturbation plots showing the effect of the independent factors on the responses; only significant effects were maintained.

The statistical parameters obtained from ANOVA for the regression models are listed in Tables III and IV.

A curvature term was added to the model, in order to check the prediction power of the factorial model in the centre of the design space. However, for all the investigated responses, curvature was found to be not significant, therefore was not considered in the final model. A probability $\mathrm{p}<0.05$ was obtained for all models, implying that they are significant (Table IV). Adjusted $\mathrm{R}^{2}$ values of $0.9886,0.9925,0.9968$ and 0.9628 respectively were obtained, suggesting a strong correlation between the observed and predicted values and therefore a good fit between the experimental model and the polynomial equations (Table III). The
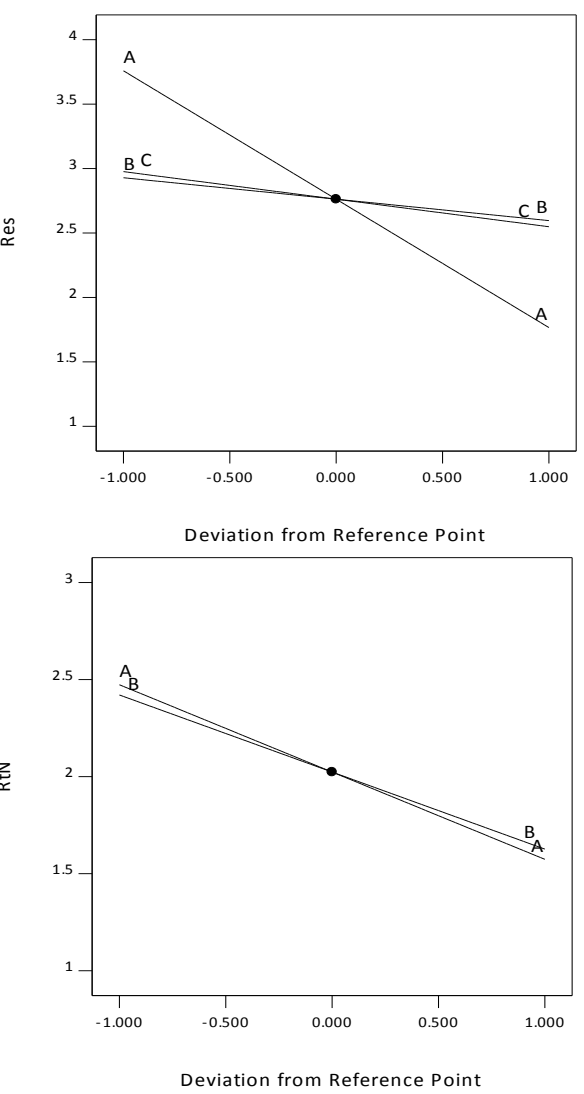

from a chosen reference point, with all other factors held constant at the reference value. A very steep slope or marked curvature for a factor indicates that the response is highly sensitive to that factor. In our case, it is to note that all perturbation plots showed low to no curvature, indicating reduced quadratic effects.

"Adequate Precision" function, a measure of the signal (response) to noise (deviation) ratio was between 46 and 168 (Table III), which indicates an adequate signal (a ratio greater than 4 being considered as desirable). The reproducibility of the model (expressed by means of the RSD \%) was also adequate $(<3 \%)$. Response surfaces and contour plots for the investigated responses are depicted in Figure 4. Since temperature has overall the lowest significance degree, only responses function of ACN percentage (A) and flow rate (B) is presented. The fact that all the surfaces formed hillsides with low curvature degrees indicated that the factors contributed mostly independently to the effects on the studied responses. 
Table III

ANOVA results for the FFD applied. Non-significant terms were excluded

\begin{tabular}{|c|c|c|c|c|c|c|c|c|}
\hline \multirow{2}{*}{ Factors } & \multicolumn{2}{|c|}{$\mathrm{Y}_{1}$-AsC } & \multicolumn{2}{|c|}{$Y_{2}$-Res } & \multicolumn{2}{|c|}{$Y_{3}$-RtC } & \multicolumn{2}{|c|}{$Y_{3}$-RtN } \\
\hline & $\mathbf{F}$ & $\mathbf{p}$ & $\mathbf{F}$ & $\mathbf{p}$ & $\mathbf{F}$ & p & $\mathbf{F}$ & $\mathbf{p}$ \\
\hline $\mathbf{A}$ & 665.50 & $<0.0001$ & 4336.17 & $<0.0001$ & 2326.38 & $<0.0001$ & 773.41 & $<0.0001$ \\
\hline B & 137.50 & $<0.0001$ & 120.75 & 0.0001 & 2914.54 & $<0.0001$ & 602.73 & $<0.0001$ \\
\hline $\mathbf{C}$ & 49.50 & 0.0004 & 199.61 & $<0.0001$ & - & - & - & - \\
\hline $\mathbf{A B}$ & - & - & - & - & - & - & - & - \\
\hline $\mathbf{A C}$ & 15.28 & 0.0079 & 59.04 & 0.0006 & - & - & - & - \\
\hline BC & - & - & 16.39 & 0.0098 & - & - & - & - \\
\hline Lack of fit & 0.4205 & 0.7913 & 4.1629 & 0.2030 & 3.5902 & 0.2338 & 16.0145 & 0.0599 \\
\hline $\mathbf{R}_{\text {adj }}^{2}$ & 0.9886 & & 0.9925 & & 0.9968 & & 0.9628 & \\
\hline
\end{tabular}

Table IV

Regression model and statistical parameters obtained from ANOVA for the investigated responses

\begin{tabular}{lcccc}
\hline Response & Regression model & $\begin{array}{c}\text { Model p- } \\
\text { value }\end{array}$ & $\begin{array}{c}\text { RSD (\%) } \\
\text { Adequate } \\
\text { precision }\end{array}$ \\
\hline $\mathbf{Y}_{\mathbf{1}}$ (AsC) & $\mathrm{Y}_{1}=1.20+0.0413 \cdot \mathrm{A}+0.0187 \cdot \mathrm{B}-0.0112 \cdot \mathrm{C}+0.0063 \cdot \mathrm{AC}$ & $<0.0001$ & 0.39 & 46.74 \\
$\mathbf{Y}_{\mathbf{2}}$ (Res) & $\mathrm{Y}_{2}=2.76-0.9963 \cdot \mathrm{A}-0.1663 \cdot \mathrm{B}-0.2138 \cdot \mathrm{C}-0.1162 \cdot \mathrm{AC}-0.0612 \cdot \mathrm{BC}$ & $<0.0001$ & 2.92 & 50.53 \\
$\mathbf{Y}_{\mathbf{3}}$ (RtC) & $\mathrm{Y}_{3}=1.74-0.3128 \cdot \mathrm{A}-0.3501 \cdot \mathrm{B}$ & 0.0004 & 1.05 & 138.41 \\
$\mathbf{Y}_{\mathbf{4}}$ (RtN) & $\mathrm{Y}_{4}=2.02-0.4498 \cdot \mathrm{A}-0.3971 \cdot \mathrm{B}$ & - & 2.26 & 60.89 \\
\hline
\end{tabular}
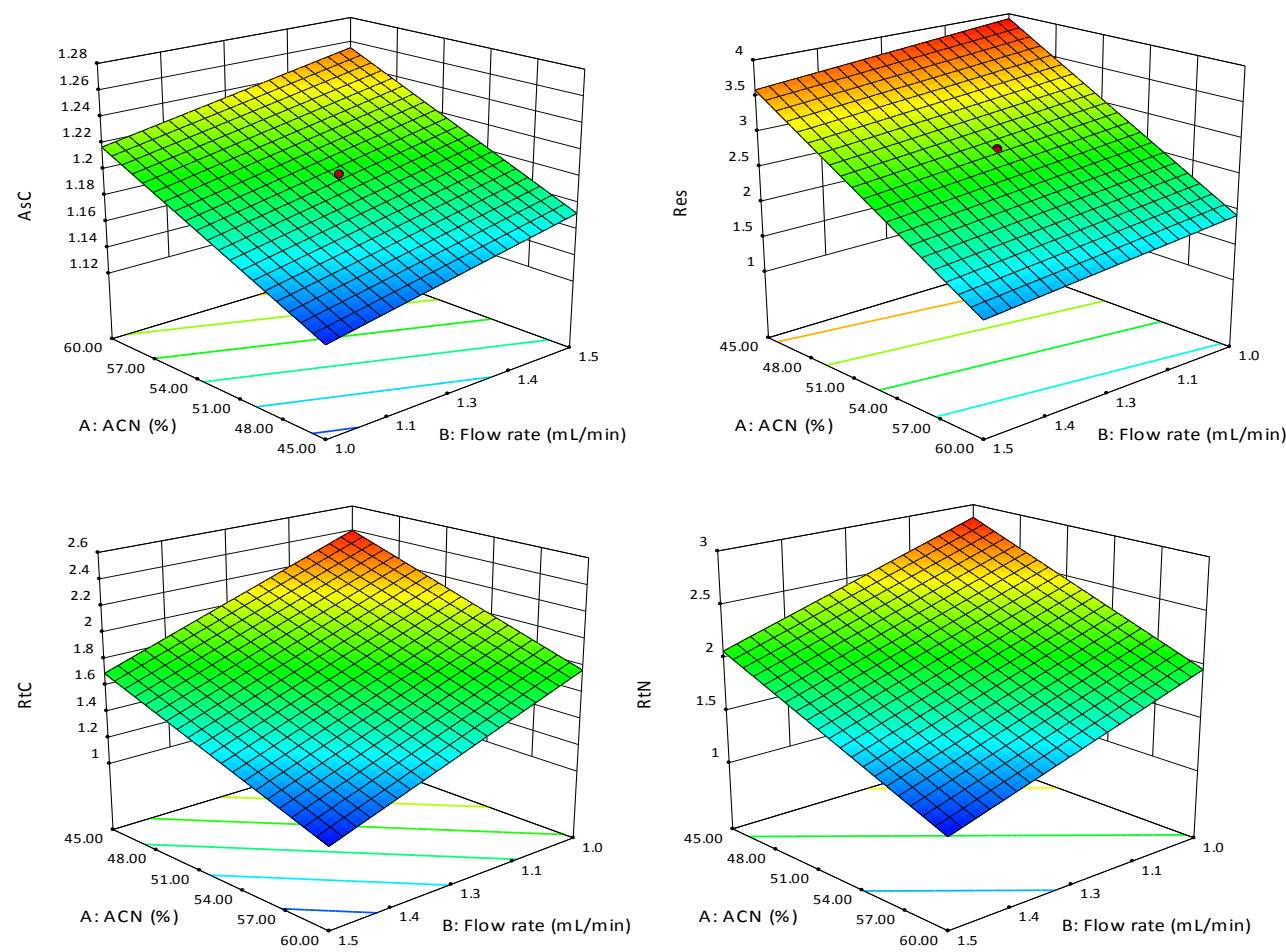

Figure 4.

Response surface and contour plots of the four evaluated responses as a function of acetonitrile percent (A) and flow rate $(B)$. Column temperature $(C)$ was kept constant at the centre value $\left(t=26^{\circ} \mathrm{C}\right)$.

For the overall optimization of the analysis parameters, both a mathematical (Derringer's desirability function) and a graphical (overlay contour plots) approach were used.

The main global objective of the method optimization process was to maximize resolution while maintaining symmetric peaks and minimizing the analysis time.
One possible approach in identifying a set of experimental conditions that optimizes all responses or at least keeps them in a desired range is by using Derringer's desirability function (D), defined as the geometric mean of the individual desirability functions [7]. A value of D of 1 signifies that the combination of the different criteria is globally optimal; hence all responses are simultaneously in the desired range. 
In order to apply the method, the target values and constraints for each response had to be defined.

In order to shorten the analysis time while separating the first eluting peak from the solvent front, the maximum resolution between $\mathrm{CBZ}$ and NTZ was targeted, while simultaneously ensuring a minimum retention time of $1.5 \mathrm{~min}$ for $\mathrm{CBZ}$, and a maximum retention time of 3 minutes for NTZ. A supplementary constraint was that the asymmetry factor for CBZ to range between 1 and 1.2.

Following the conditions and restrictions presented above, the response surface plot obtained for desirability function is presented in Figure 5, with the maximum desirability obtained for A: $45 \%$ ACN, B: $1 \mathrm{~mL} / \mathrm{min}$ and $\mathrm{C}: 22^{\circ} \mathrm{C}$.

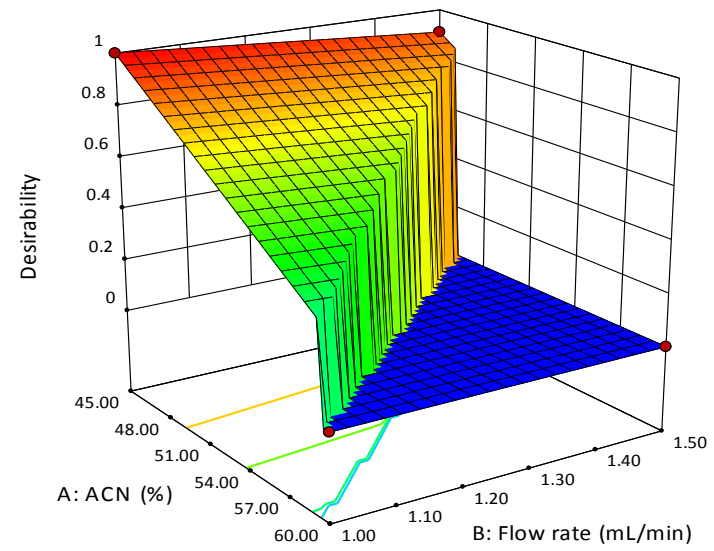

Figure 5.

Graphical representation of the overall desirability function D. Flow Rate (B) is plotted against ACN percentage $(\mathrm{A})$, with temperature $(\mathrm{C})$ held constant at $22^{\circ} \mathrm{C}$

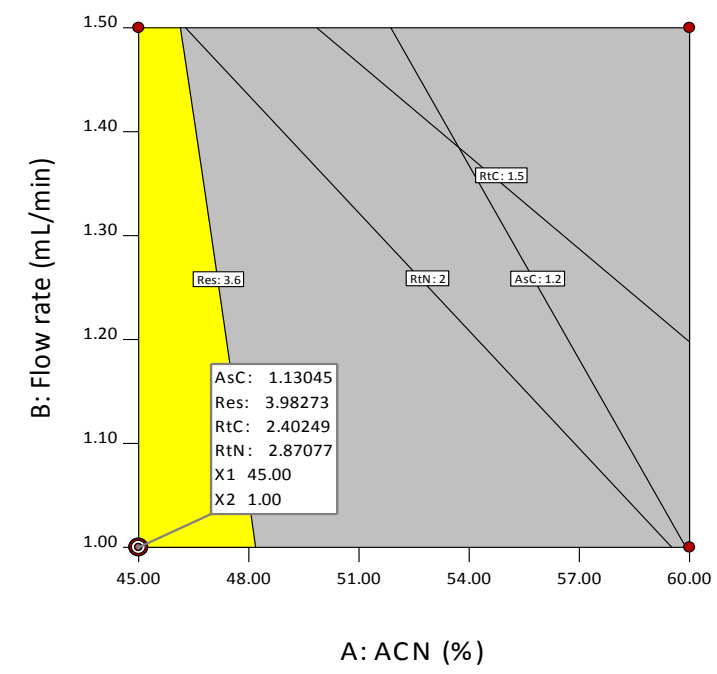

Figure 6.

Identification of the Design Space using overlay plot of effects: yellow region indicates Design Space, whilst in the grey region the responses are below the desired level
Using the contour plot approach (Figure 6), the Design Space can be identified.

\section{Method validation}

The aim of the validation was to establish that the analytical method is suitable for quantitative determination of CBZ from plasma samples. Several widely recognized validation criteria were evaluated (selectivity, linearity, limit of quantification, accuracy, precision, recovery and stability), in accordance with the FDA guidelines [10].

Selectivity of the optimized chromatographic method was emphasized based on the ability of the assay to separate CBZ and NTZ from plasma samples without interference from any endogenous material.

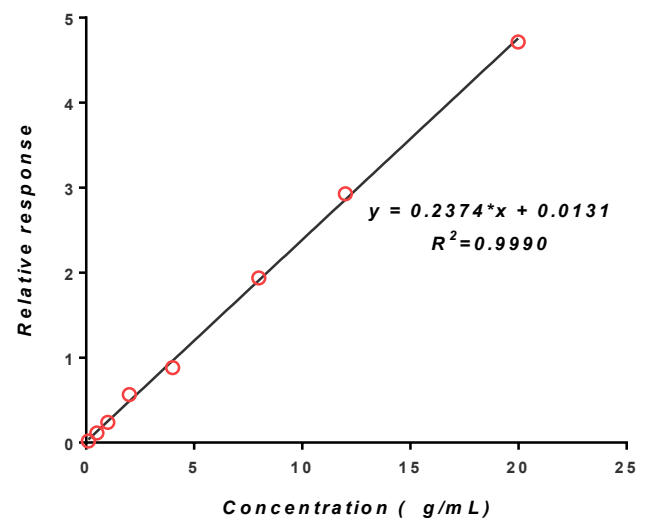

Figure 7.

Calibration curve for CBZ in the range $0.1-20 \mu \mathrm{g} / \mathrm{mL}$

The calibration curve, constructed by plotting the average response factors (peak-area ratios of the CBZ to the internal standard) obtained for 8 different CBZ levels against the nominal concentrations of was linear in the range of $0.1-20.0 \mu \mathrm{g} / \mathrm{mL}$, with a correlation coefficient $\mathrm{R}^{2}=0.9990$ (Figure 7).

The therapeutic range of carbamazepine is reported to be in the range of $6-12 \mu \mathrm{g} / \mathrm{mL}$ [6], therefore is fully included in the linearity domain, making the method appropriate for the intended use, namely TDM.

Based on the signal-to-noise ratio, a value of 0.1 $\mu \mathrm{g} / \mathrm{mL}$ was established as LOQ for the method (Figure 8).

The intra-day and inter-day accuracy (expressed as the $\%$ bias from the true value) and precision (evaluated based on the \% RSD) were determined for the QC samples. Assay accuracy (\% bias) ranged from $-3.39 \%$ to $5.03 \%$, and precision $(\%$ RSD) ranged from $0.83 \%$ to $7.70 \%$ as shown in Table V, being well within the accepted values. 


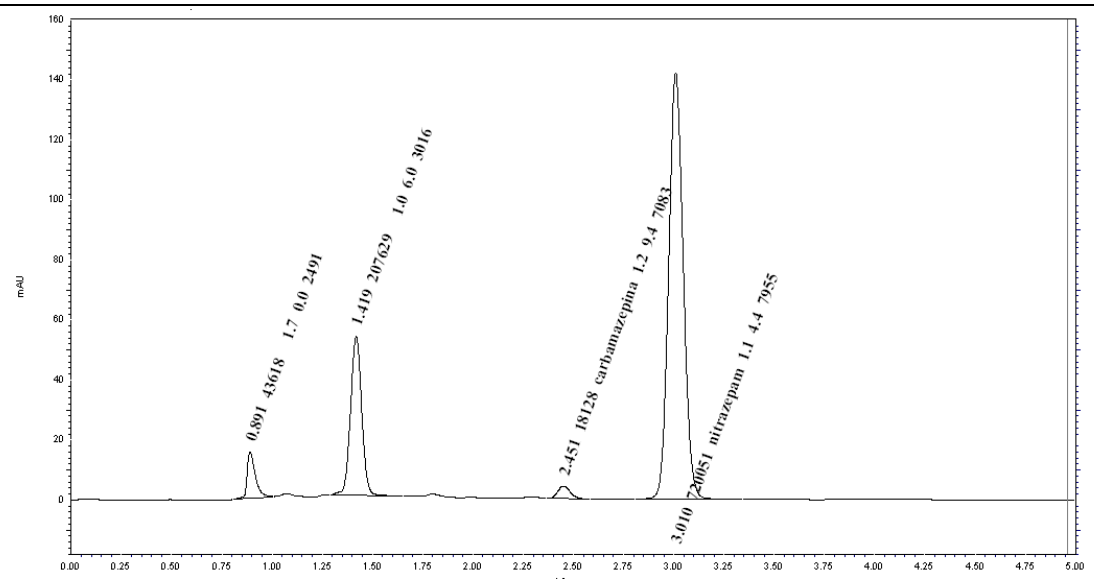

Figure 8.

Representative chromatogram of a plasma sample spiked with CBZ at the LOQ level

Table V

Intra- and inter-day accuracy (\% Bias) and precision (\% RSD) of the method

\begin{tabular}{ccccccc}
\hline \multirow{2}{*}{ Nominal concentration } & \multicolumn{2}{c}{ Intra-day } & & \multicolumn{2}{c}{ Inter-day } \\
\cline { 2 - 3 } \cline { 5 - 7 } & \% Bias & \% RSD & & \% Bias & \% RSD \\
\hline 0.1 & 4.40 & 7.12 & & -3.39 & 7.70 \\
12 & 5.03 & 2.72 & & 2.31 & 2.79 \\
20 & -1.19 & 0.86 & & 2.35 & 0.83 \\
\hline
\end{tabular}

The stock solutions of CBZ and NTZ were stable for at least three months when maintained in the refrigerator, whereas the study samples were stabile when maintained for 21 days at $-20^{\circ} \mathrm{C}$ and after three freeze-thaw cycles. The processed samples were stable in the autosampler for at least 24 hours.

Application of the method for therapeutic drug monitoring

The applicability of the developed method was assessed by analysing a real plasma sample of a patient undergoing CBZ treatment (200 mg daily dose administered orally). Whole blood sample was obtained from a 74-year-old woman, with a body weight of $72 \mathrm{~kg}$. Written consent of the volunteer was obtained. Blood samples were taken in the morning, one hour after administration of the medicine. A sample chromatogram obtained after analysis of the patient sample is presented in Figure 9. The CBZ concentration in the sample was $4.8 \mu \mathrm{g} / \mathrm{mL}$

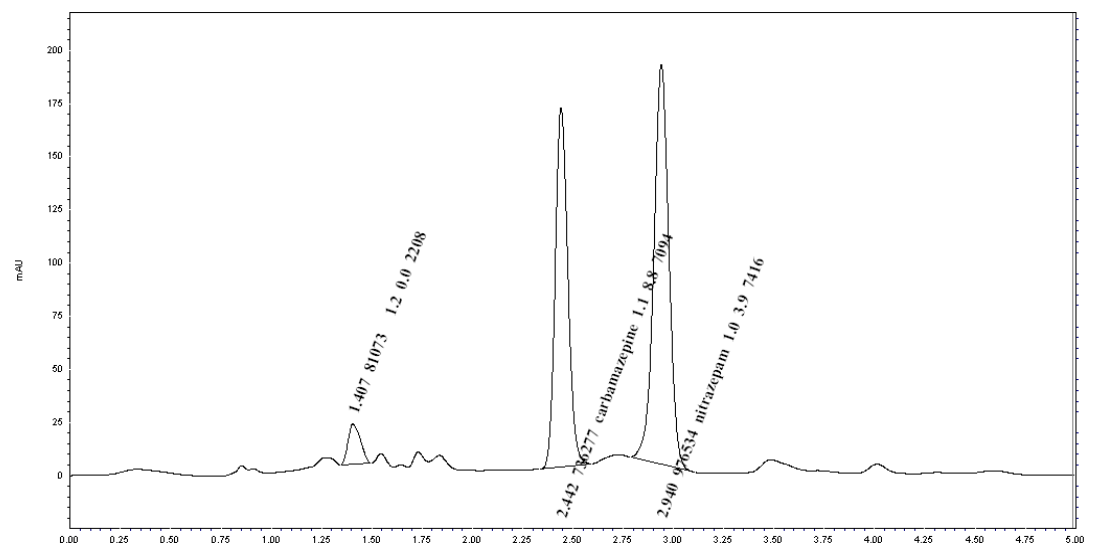

Figure 9.

Chromatogram obtained at 1 hour after the oral administration of $200 \mathrm{mg} \mathrm{CBZ}$ to a patient undergoing CBZ treatment.

\section{Conclusions}

A simple and fast chromatographic method used for the determination of carbamazepine in human plasma has been developed and validated. The acceptance criteria were met for all validation parameters. The method was successfully applied for therapeutic drug monitoring and can also be used in pharmacokinetic, bioequivalence and permeability studies. 


\section{References}

1. Ababei DC, Chiriac SB, Bild W, Solcan C, Luca A, Rusu RN, Bulea D, Bild V Synergistic effecs ot the doxepin-candesartan combination on the thermoalgesic sensibility in mice. Farmacia, 2017; 65(5): 726-730.

2. Anuța V, Nițulescu GM, Dinu-Pîrvu CE, Olaru OT, Biopharmaceutical profiling of new antitumor pyrazole derivatives. Molecules, 2014; 19(10): 16381-16401.

3. Anuța V, Sârbu I, Mircioiu I, Velescu B, Development of a new HPLC method for simultaneous determination of clopidogrel and its major metabolite using a chemometric approach. Current Health Sciences Journal, 2015; 41(1): 1121.

4. Baconi DL, Stan M, Abdul Jalil Ebrahim Z, Tuchila C, Balalau C, Determination of Tramadol in human plasma by HPLC with fluorescence detection. J Mind Med Sci., 2016; 3(1): 55-64.

5. Behbahani M, Najafi F, Bagheri S, Bojdi MK, Salarian M, Bagheri A, Application of surfactant assisted dispersive liquid-liquid microextraction as an efficient sample treatment technique for preconcentration and trace detection of zonisamide and carbamazepine in urine and plasma samples. $J$ Chromatography A, 2013; 1308: 25-31.

6. Brunton LL, Chabner B, Knollmann BC, eds. Goodman \& Gilman's - The Pharmacological Basis of Therapeutics. $12^{\text {th }}$ ed. 2011.

7. Costa NR, Lourenço J, Pereira ZL, Desirability function approach: a review and performance evaluation in adverse conditions. Chemometrics Intelligent Lab. Sys., 2011; 107(2): 234-244.

8. Džodić P, Živanović L, Protić A, Ivanović I, Veličković-Radovanović R, Spasić M, Lukić S, Živanović S, Development and validation of SPEHPLC method for the determination of carbamazepine and its metabolites carbamazepine epoxide and carbamazepine trans-diol in plasma. $J$ Serbian Chem Soc., 2012; 77(10): 1423-1436.

9. Ezzeldin E, Shahat AA, Basudan OA, Development and Validation of an HPLC Method for the Determination of Carbamazepine in Human Plasma. Life Sci J., 2013; 10(4): 2159-2163.

10. FDA. Guidance for industry: bioanalytical method validation. Food and Drug Administration - Center for Drug Evaluation and Research (CDER)/Center for Veterinary Medicine (CVM): Rockville, MD, USA. 2013. Available from: www.fda.gov/Drugs.

11. Ferreira A, Rodrigues M, Falcão A, Alves G, HPLC-DAD method for the quantification of carbamazepine, oxcarbazepine and their active metabolites in HepaRG cell culture samples. Chromatographia, 2016; 79(9-10): 581-590.

12. Ghica M, Albu M, Popa L, Moisescu S, Response surface methodology and Taguchi approach to assess the combined effect of formulation factors on minocycline delivery from collagen sponges. Die Pharmazie-An Int J Pharmaceutical Sci., 2013; 68(5): 340-348.

13. Ghica MV, Albu Kaya MG, Dinu-Pîrvu CE, Lupuleasa D, Udeanu DI, Development, Optimization and In
Vitro/In Vivo Characterization of Collagen-Dextran Spongious Wound Dressings Loaded with Flufenamic Acid. Molecules, 2017; 22(9): 1552.

14. Greenberg RG, Melloni C, Wu H, Gonzalez D, Ku L, Hill KD, Hornik CP, Zheng N, Jiang W, CohenWolkowiez M, Therapeutic index estimation of antiepileptic drugs: a systematic literature review approach. Clin Neuropharmacology, 2016; 39(5): 232.

15. Hibbert DB, Experimental design in chromatography: a tutorial review. J Chromatography B, 2012; 910: 2-13.

16. Hu L, Liu Y, Cheng S, Simultaneous determination of six analytes by HPLC-UV for high throughput analysis in permeability assessment. J Chromatographic Sci., 2011; 49(2): 124-128.

17. Krasowski MD, McMillin GA, Advances in antiepileptic drug testing. Clin Chim Acta, 2014; 436: 224-236.

18. Mashayekhi HA, Abroomand-Azar P, Saber-Tehrani M, Husain SW, Rapid determination of carbamazepine in human urine, plasma samples and water using DLLME followed by RP-LC. Chromatographia, 2010; 71(5-6): 517-521.

19. McMillin GA, Juenke JM, Tso G, Dasgupta A, Estimation of carbamazepine and carbamazepine-10,11epoxide concentrations in plasma using mathematical equations generated with two carbamazepine immunoassays. Am J Clin Pathology, 2010; 133(5): 728-736.

20. Mowafy HA, Alanazi FK, El Maghraby GM, Development and validation of an HPLC-UV method for the quantification of carbamazepine in rabbit plasma. Saudi Pharmaceutical J., 2012; 20(1): 29-34.

21. Patel RB, Patel MR, Bhatt KK, Patel BG, Development and validation of HPTLC method for estimation of carbamazepine in formulations and its in vitro release study. Chromatography Res Intern., 2011; 2011(ID 684369): 1-8.

22. Patil SR, Kumar L, Kohli G, Bansal AK, Validated HPLC method for concurrent determination of antipyrine, carbamazepine, furosemide and phenytoin and its application in assessment of drug permeability through Caco-2 cell monolayers. Scientia Pharmaceutica, 2011; 80(1): 89-100.

23. Patsalos PN, Berry DJ, Bourgeois BF, Cloyd JC, Glauser TA, Johannessen SI, Leppik IE, Tomson T, Perucca E, Antiepileptic drugs-best practice guidelines for therapeutic drug monitoring: a position paper by the subcommission on therapeutic drug monitoring, ILAE Commission on Therapeutic Strategies. Epilepsia, 2008; 49(7): 1239-1276.

24. Shokry E, Villanelli F, Malvagia S, Rosati A, Forni G, Funghini S, Ombrone D, Della Bona M, Guerrini R, La Marca G, Therapeutic drug monitoring of carbamazepine and its metabolite in children from dried blood spots using liquid chromatography and tandem mass spectrometry. J Pharmaceutical Biomed Analysis, 2015; 109: 164-170.

25. Sultana N, Arayne MS, Ali SN, An ultra-sensitive LC method for the simultaneous determination of paracetamol, carbamazepine, losartan and ciprofloxacin in bulk drug, pharmaceutical formulation and human serum by programming the detector. Am J Analytical Chem., 2013; 4(1): 24-33. 
FARMACIA, 2018, Vol. 66, 3

26. Toderescu CD, Dinu-Pîrvu C, Ghica MV, Anuța V, Popa DE, Vlaia L, Lupuliasa D, Influence of formulation variables on ketoprofen diffusion profiles from hydroalcoholic gels. Farmacia, 2016; 64(5): 728-735.

27. Tonic-Ribarska J, Sterjev Z, Cvetkovska E, Kiteva G, Suturkova L, Trajkovic-Jolevska S, Optimization and validation of bioanalytical SPE-HPLC method for the simultaneous determination of carbamazepine and its main metabolite, carbamazepine-10,11-epoxide, in plasma. Macedonian Pharm Bull., 2011; 57(1-2): 53-61.
28. Tuchilă C, Baconi DL, Dinu Pîrvu C, Balalau DO, Vlasceanu AM, Stan M, Balalau C, Therapeutic Drug Monitoring and Methods of Quantitation for Carbamazepine. J Mind Med. Sci., 2017; 4(2): 100-114.

29. Vosough M, Ghafghazi S, Sabetkasaei M, Chemometrics enhanced HPLC-DAD performance for rapid quantification of carbamazepine and phenobarbital in human serum samples. Talanta, 2014; 119: 17-23. 